\title{
Dual novel mutations in SLC26A2 in two siblings with multiple epiphyseal dysplasia 4 from a Chinese family: a case report
}

\author{
Taifeng Zhou ${ }^{1,2+}{ }^{+}$Yongqian Wang ${ }^{3 \dagger}$, Hang Zhou ${ }^{1,2+}$, Zhiheng Liao ${ }^{1,2}$, Bo Gao ${ }^{4}$, Deying Su ${ }^{1,2}$, Shuhui Zheng ${ }^{5}$, \\ Caixia $\mathrm{Xu}^{5^{*}}$ and Peiqiang $\mathrm{Su}^{1,2^{*}}$ (D)
}

\begin{abstract}
Background: Multiple epiphyseal dysplasia (MED) is a heterogeneous genetic condition characterized by variable phenotypes, such as short stature (mild to moderate), joint deformities, abnormal gait, scoliosis, and brachydactyly. Recessive mutations in the SLC26A2 gene cause a phenotype of multiple epiphyseal dysplasia-4 (MED-4). In the present study, we identified novel compound heterozygous mutations in the SLC26A2 gene in a Chinese family with two affected sibs with MED-4.

Case presentation: Radiographs revealed hip dysplasia, brachydactyly and scoliosis in patient 1. Radiological examinations in patient 2 also showed hip dysplasia recently. Both of them were diagnosed with MED-4. SLC26A2 c. 824 T > C and SLC26A2 C.1198C > T were identified in two siblings in this family, which were inherited from both parents, one mutation from each.

Conclusions: This is the first Chinese MED-4 family attributed to SLC26A2 mutations, and these results show that these novel compound heterozygous mutations in SLC26A2 contribute to MED-4.
\end{abstract}

Keywords: Multiple epiphyseal dysplasia, SLC26A2, Targeted next-generation sequence, Compound heterozygote

\section{Background}

Multiple epiphyseal dysplasia (MED) is a heterogeneous genetic condition characterized by variable phenotypes, such as short stature (mild to moderate), joint deformities, abnormal gait, and early-onset osteoarthritis [1]. MED is associated with structural anomalies in epiphyses and delayed ossification of the epiphyses with small, irregular ossification centers, resulting in moderate shortening. Patients usually appear normal at birth and have good muscular development and normal intelligence [2].

Mutations in the following six genes, COMP (MIM 600310) [3], COL9A1 (MIM 120210) [4], COL9A2 (MIM

\footnotetext{
* Correspondence: xucx3@mail.sysu.edu.cn; supq@mail.sysu.edu.cn

${ }^{\dagger}$ Equal contributors

${ }^{5}$ Research Centre for Translational Medicine, First Affiliated Hospital of Sun Yat-sen University, No. 58 Zhongshan 2nd Road, Yuexiu District, Guangzhou 510080, China

${ }^{1}$ Department of Orthopaedic Surgery, First Affiliated Hospital of Sun Yat-sen University, No.58 Zhongshan 2nd Road, Yuexiu District, Guangzhou 510080, China

Full list of author information is available at the end of the article
}

120260) [5], COL9A3 (MIM 120270) [6], MATN3 (MIM 602109) [7], and solute carrier family 26 member 2 (SLC26A2, MIM 606718) [8], have been found to be related to MED. SLC26A2 exhibits autosomal recessive inheritance, but the other five genes show an autosomal dominant manner. Mutations in the SLC26A2 result in a family of skeletal dysplasias depending on the residual sulfate transporter activity, which range in severity from the very severe achondrogenesis type IB (MIM 600972) [9], atelosteogenesis type II (MIM 256050) [10], and diastrophic dysplasia (MIM 222600) [11] to the relatively mild recessive multiple epiphyseal dysplasia-4 (MED-4, MIM 226900). The homozygous mutation c.835C $>\mathrm{T}$ (p.Arg279Trp) is the most common mutation in the SLC26A2 gene, resulting in MED-4 with short stature, multiple epiphyseal dysplasia, scoliosis, double layered patella, brachydactyly and clubfoot $[8,12,13]$.

We present two siblings with MED-4 from an eastern Chinese family. Genetic analysis revealed compound heterozygotes for two novel heterozygous mutations in

(c) The Author(s). 2018 Open Access This article is distributed under the terms of the Creative Commons Attribution 4.0 International License (http://creativecommons.org/licenses/by/4.0/), which permits unrestricted use, distribution, and reproduction in any medium, provided you give appropriate credit to the original author(s) and the source, provide a link to the Creative Commons license, and indicate if changes were made. The Creative Commons Public Domain Dedication waiver (http://creativecommons.org/publicdomain/zero/1.0/) applies to the data made available in this article, unless otherwise stated. 
SLC26A2. Further genetic studies and clinical evaluation of their parents revealed that these two mutations were from their father and mother, respectively. This study reported that compound heterozygous mutations in SLC26A2 contributed to MED-4.

\section{Case presentation}

\section{Patient 1}

\section{Clinical findings}

A 12-year-old girl was born normally to nonconsanguineous, healthy eastern Chinese parents after a normal pregnancy. The body length at birth was $51 \mathrm{~cm}$. She was referred to our hospital for diagnosis and treatment. There was no family history of endocrine diseases and musculoskeletal problems. Her parents noticed unequal leg lengths around the age of 6 years and radiography revealed coxa plana. Abnormal gait and limping were noticed at 9 years. The rotation function of the right leg was limited. For these reasons, she underwent right hip arthroplasty and resection of cartilago acetabularis in another hospital. Postoperative pathology revealed chronic synovitis. Half a year after the surgery, a lump with high skin temperature was noticed by her parents in the left femoribus internus. The flexion-extension function of the left leg was limited. Physical examination revealed the following: height $138 \mathrm{~cm}$. Her intellectual development and hearing were normal. She had brachydactyly, bilateral skewfoot, and lumbosacral scoliosis. The movements of both hips were limited. She did not have a cleft palate, cephalofacial deformities, or respiratory insufficiency. Routine analysis for common skeletal dysplasia excluded any thyroid or growth hormone disorders and immunopathies. Upon analysis, bone metabolism appeared normal.

\section{Radiological findings}

Radiological documentation at the ages of 7 and 12 years revealed hip dysplasia with the following deformities: short femoral necks, flattened and irregular femoral heads, and early closure of epiphysis (Fig. 1a). Spinal radiographs at the ages of 11 and 12 years confirmed evolving scoliosis, which appeared to be structural vertebral deformity (Fig. 1b). Hand radiographs confirmed the brachydactyly and significantly flattened articular surface. The metacarpi and phalanges were mild shorten (Fig. 1c).

\section{a}
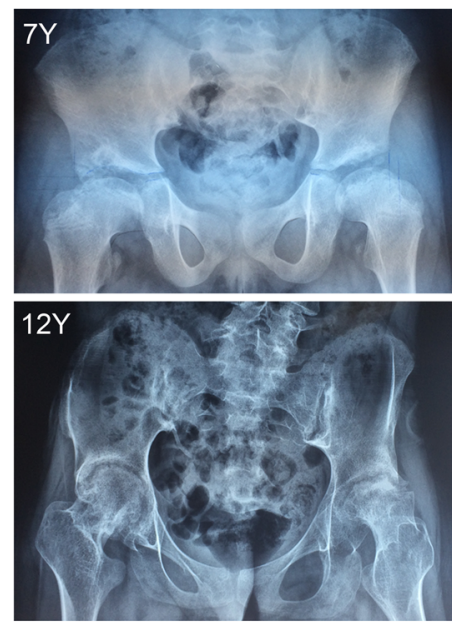

C

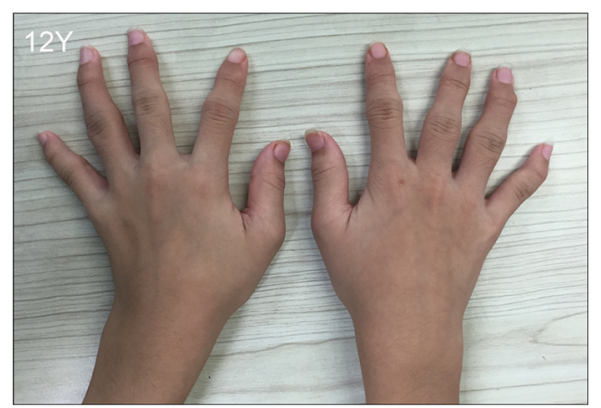

\section{b}
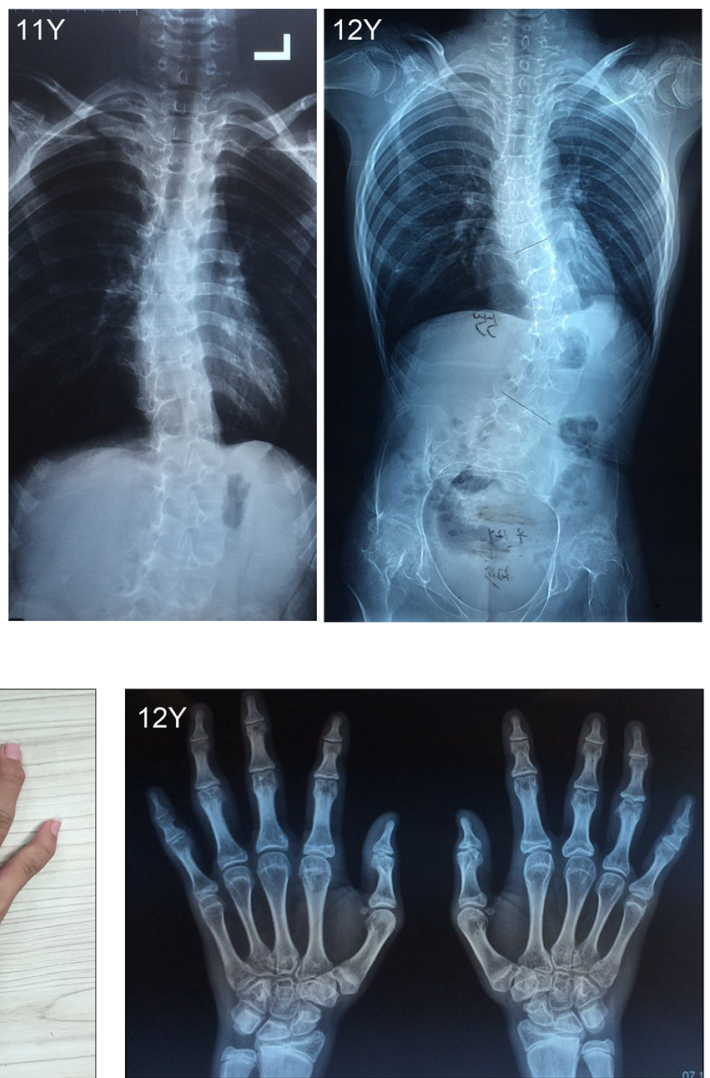

Fig. 1 Radiographs and clinical features of patient 1. Hip radiographs revealed coxa plana at the ages of 7 and 12 years (a). Spinal radiographs confirmed the progress of scoliosis (b). Hand radiographs confirmed the brachydactyly and significantly flattened articular surface (c-d) 


\section{Patient 2}

\section{Clinical findings}

A 6-year-old boy, the younger brother of patient 1, was also born to the same parents. The pregnancy was normal, and he was normal at birth without cleft palate or cephalofacial deformities. The body length at birth was $50 \mathrm{~cm}$. An abnormal gait, waddling with short steps, was also noticed recently.

\section{Radiological findings}

Roentgenologic bone survey showed hip dysplasia with the following abnormalities: both femoral necks were short with flattened heads; acetabulum dysplasia, and secondary ossification center of femur dysplasia (Fig. 2).

\section{Molecular data}

Written informed consent was obtained from the parents of patient 1 and patient 2. Genomic DNA was extracted from peripheral blood using an e.Z.N.A. ${ }^{\circledR}$ Blood DNA Kit (Omega Bio-tek, Norcross, GA, USA) according to the manufacturer's protocol. A total of 363 genes, including COL1A1, COL1A2, COL11A1, and other related genes, were analyzed by Targeted NGS in patient 1 . The total size of the target regions of the capture array was 3 . $0 \mathrm{Mb}$. After filtering out common variants and neutral or benign mutations (allele frequency of $\geq 0.5 \%$ in $\mathrm{dbSNP}$
(http://www.ncbi.nlm.nih.gov/projects/SNP/), the 1000 Genomes Pilot Project Data (http://www.1000genomes.org/) or BGI in-house database, which includes 1092 normal subjects.), two mutations, SLC26A2 c.824 T>C (NM 000112.3) and SLC26A2 c.1198C $>\mathrm{T}$ were identified (Fig. 3a). Both variants were absent from all databases, including 1000genomes, dbsnp, ESP6500, and the BGI in-house database, and both variants were predicted as functional damaging in MutationTaster, Polyphen-2 and SIFT (Table 1). Both of the two mutations are evolutionarily conserved (Fig. 3b). Then sanger sequencing revealed two variants in patient 2; SLC26A2 c.824 T > C and SLC26A2 c. $1198 \mathrm{C}>\mathrm{T}$ were identified in Mother and Father, respectively (Fig. 3c).

\section{Discussion and conclusion}

Multiple epiphyseal dysplasia is a heterogeneous group of skeletal dysplasias characterized by dysplastic epiphyses at multiple sites [14]. Superti-Furga et al. first reported a homozygous SLC26A2 mutation (c.835C > T, p. Arg279Trp) in a 36-year-old man of tall-normal stature with MED-4 [12]. Variable phenotype with variable joint manifestations and normal to short stature were described in 18 individuals with MED-4 [8]. The deformity of clubfoot was observed in approximately $28 \%$ of the MED-4 patients. The most frequent radiographic finding
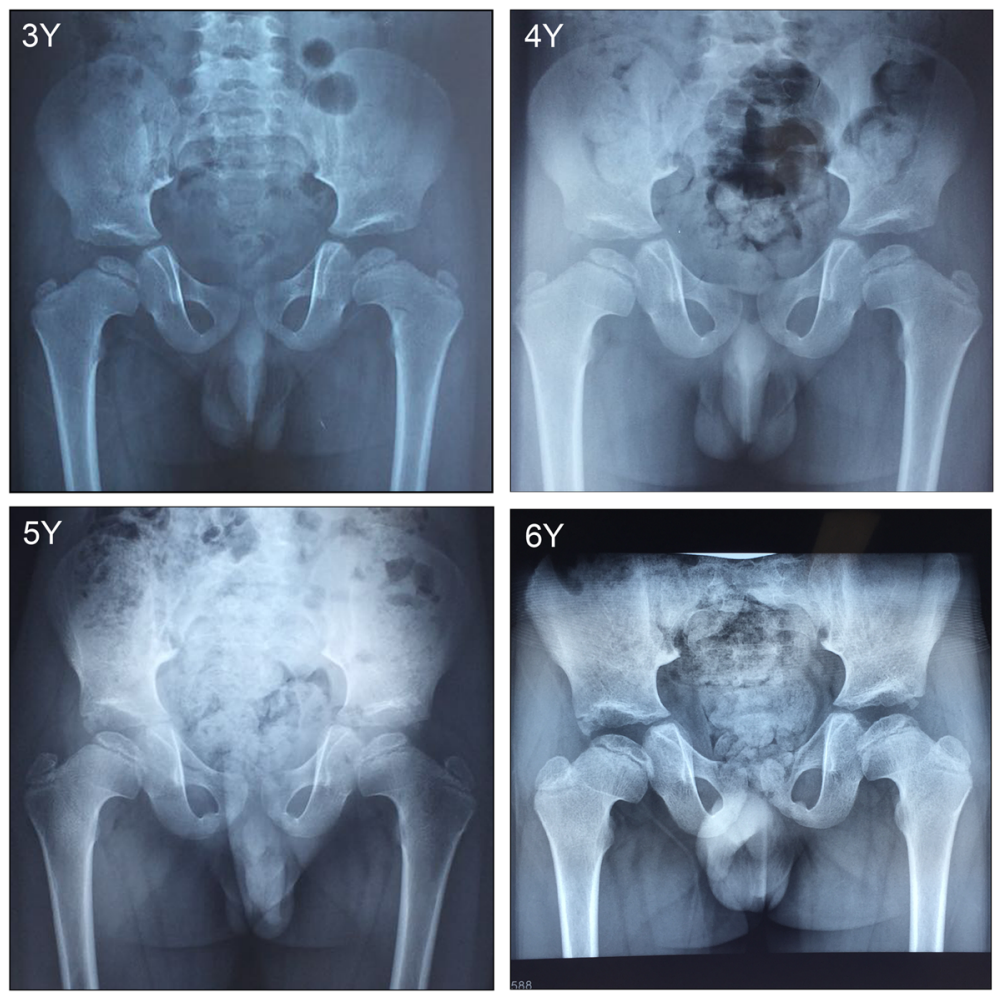

Fig. 2 Hip radiographs of patient 2 during the ages from 3 to 6 years. Roentgenologic bone survey showed hip dysplasia with the following abnormalities: both femoral necks were short with flattened heads, acetabulum dysplasia, and secondary ossification center of femur dysplasia 


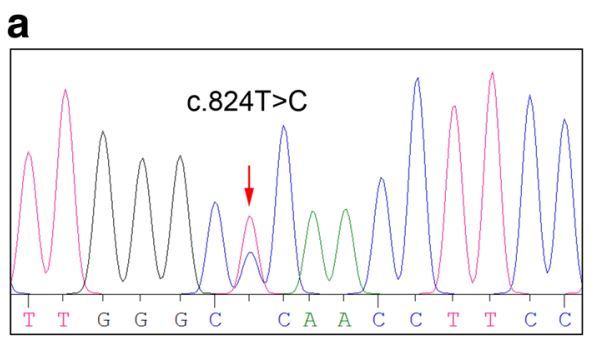

C
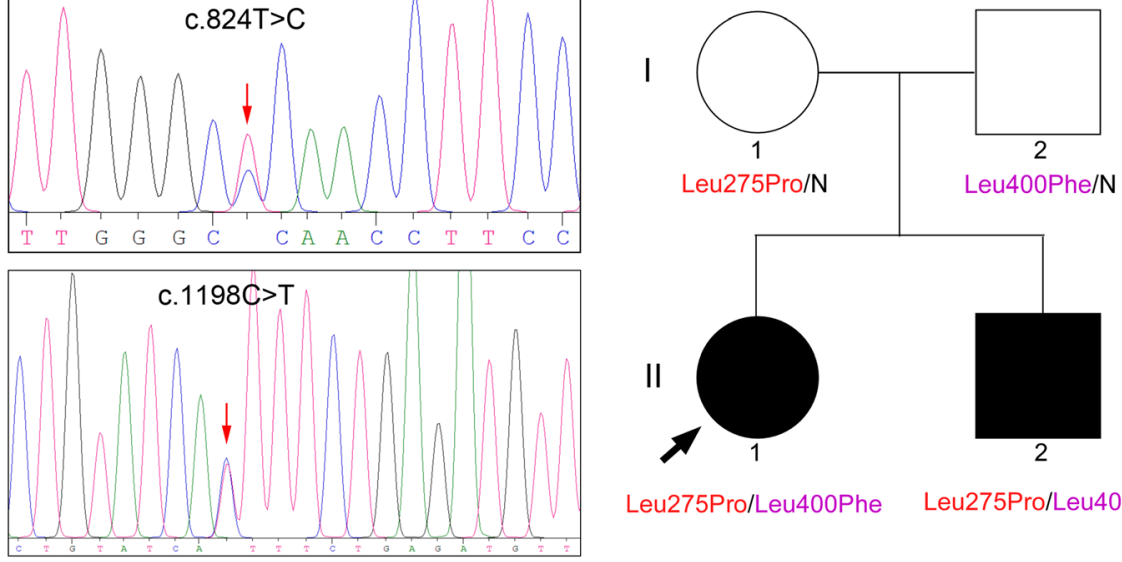

Leu275Pro/Leu400Phe Leu275Pro/Leu400Phe

b

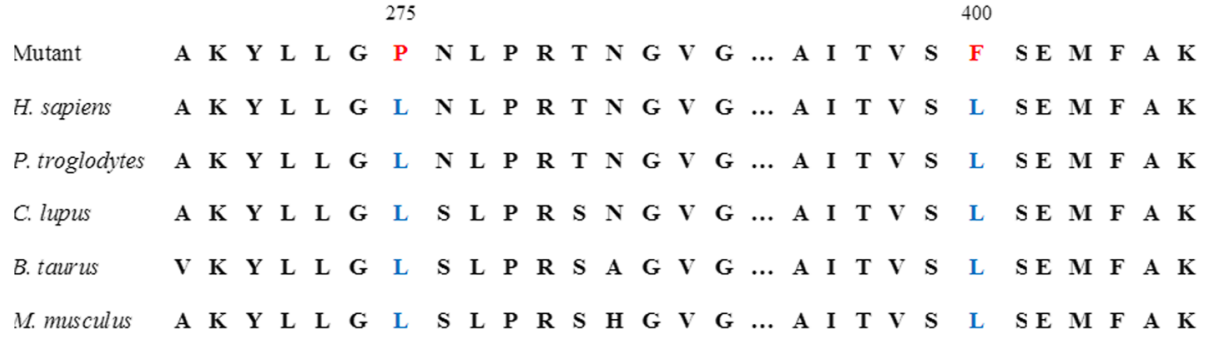

Fig. $\mathbf{3}$ The missense mutations in SLC26A2 in patient 1 and family pedigree. Sanger sequencing results revealed novel compound heterozygous mutations (a) in SLC26A2 contributing to MED-4 (c). Both of these mutations are evolutionarily conserved (b)

was mild to moderate hip dysplasia. Only one patient had undergone hip replacement surgery for hip dysplasia. That patient required varisation osteotomies of both femoral necks. Other characteristic findings included brachydactyly and scoliosis [14]. A double-layer patella seems to be specific but not essential to MED-4 and when present, separates the condition from the dominant forms of MED caused by mutations in COMP, COL9, and Matrilin-3.

In the present study, the presence of short stature, coxa plana, brachydactyly, abnormal gait, and scoliosis in Patient 1 led to the clinical diagnosis of MED-4. Very recently, the abnormal gait and coxa plana were noticed in the younger brother, Patient 2 , at the same age as his elder sister did at 6 years. To verify the cause of the disease, we suggested their parents to authorize a genetic analysis using an available capture array, which covers 363 genes related to bone diseases, including COL1A1, COL1A2, COL11A1, SLC26A2, COMP, COL9A1, and other genes. Indeed, the younger brother harbored the same mutations in SLC26A2. We then suspected him to be at the early stage of MED-4, and we advised his parents to be cautious regarding the development of epiphyseal dysplasia in the future.

Mutations in SLC26A2 are related to a wide range of phenotypes, depending on the residual sulfate transporter activity. These phenotypes range in severity from the very severe achondrogenesis type IB, atelosteogenesis type II, and diastrophic dysplasia to the relatively mild recessive MED-4. The most common SLC26A2 mutation reported in several studies is homozygous c. 835C > T (p.Arg279Trp) [15]. Karniski compared the sulfate transport activity of 11 SLC26A2 mutations in the Xenopus laevis oocyte expression system [16]. Their results indicated that the p.Arg279Trp mutation transported sulfate at a rate 32\% that of wild-type SLC26A2, while some mutations had minimal residual sulfate transport function. Makitie et al. reported another

Table 1 Functional prediction of SLC26A2 mutations

\begin{tabular}{llllllll}
\hline Chr. & Position & Gene symbol & Transcript variant & Protein variant & MutationTaster score & PolyPhen-2 & SIFT score \\
\hline 5 & 149359980 & SLC26A2 & C.824 T > C & p.Leu275Pro & 0.999 & 0.999 & 0.000 \\
5 & 149360354 & SLC26A2 & c.1198C $>$ T & p.Leu400Phe & 0.999 & 1.000 & 0.002 \\
\hline
\end{tabular}


homozygous SLC26A2 mutation, c.1957 T > A (p.Cys653Ser), in two unrelated patients with hip dysplasia, recurrent patella dislocation, and normal stature [14]. Very recently, a patient from a Caucasian three-generational family with MED-4 was reported to be a compound heterozygote for the common mutation in SLC26A2 and a novel mutation, p.Ser522Phe, while her maternal grandfather was homozygous for the common mutation [15]. Using a skeletal dysplasia targeted NGS panel, two novel heterozygous SLC26A2 mutations were identified in $\mathrm{Pa}-$ tient 1 . These mutations, c.824 $\mathrm{T}>\mathrm{C}$ (p.Leu275Pro) and c. $1198 \mathrm{C}>\mathrm{T}$ (p.Leu400Phe), are located in the extracellular loop (between amino acids 263 and 296) and the cytoplasmic loop (between amino acids 399 and 420), respectively. Both mutations were predicted to be functionally deleterious and missing in the above-mentioned databases. However, no functional studies have been undertaken for both mutations, so we do not know exactly if these are severe or mild mutations. Sanger sequencing confirmed that these mutations in Patients 1 and 2 came from their parents, one mutation from each. Clinical features and genetic analysis suggested that in this Eastern Chinese family, both patients were also compound heterozygotes for two novel SLC26A2 mutations.

In conclusion, we present two patients of MED-4 with evolving clinical and radiological features. Skeletal surveys, joint complications, and genetic testing of their parents were found to be essential to understanding the mechanism. Both patients were compound heterozygotes for two unreported mutations in SLC26A2, c.824 T > C (p.Leu275Pro) and c.1198C > T (p.Leu400Phe).

\section{Abbreviations}

DNA: Deoxyribonucleic acid; MED: Multiple epiphyseal dysplasia; MED4: Multiple epiphyseal dysplasia, type 4; MIM: Mendelian inheritance in man; SIFT: Sorting intolerant from tolerant; Targeted NGS: Targeted nextgeneration sequencing

\section{Acknowledgments}

We would like to thank Accdon (www.accdon.com) for providing linguistic assistance during the preparation of this manuscript.

\section{Funding}

This research was supported by the National Natural Science Foundation of China (No. 81572091, 81772293, and 81772302) and the Guangzhou Science and Technology Program (201704020120).

\section{Availability of data and materials}

The datasets used and/or analyzed during the current study are available from the corresponding authors on reasonable request.

\section{Authors' contributions}

TZ, YW and HZ drafted manuscript; TZ, YW, HZ and PS performed the clinical assessments of the patients and characterized the patients clinically; ZL, BG and DS contributed to the targeted next-generation sequencing and sanger sequencing; SZ and CX contributed to the mutation analysis. All authors read and approved the final manuscript.
Ethics approval and consent to participate

This study was approved by the Ethical Committees of the First Affiliated Hospital of Sun Yat-sen University. Written informed consent was obtained from the parents of patient 1 and patient 2 .

\section{Consent for publication}

The parent of the patients consented to the publication of the case and any accompanying images with written consent.

\section{Competing interests}

The authors declare that they have no competing interests.

\section{Publisher's Note}

Springer Nature remains neutral with regard to jurisdictional claims in published maps and institutional affiliations.

\section{Author details}

${ }^{1}$ Department of Orthopaedic Surgery, First Affiliated Hospital of Sun Yat-sen University, No.58 Zhongshan 2nd Road, Yuexiu District, Guangzhou 510080, China. ${ }^{2}$ Guangdong Provincial Key Laboratory of Orthopedics and Traumatology, First Affiliated Hospital of Sun Yat-sen University, Guangzhou 510080, China. ${ }^{3}$ Department of Musculoskeletal Oncology, First Affiliated Hospital of Sun Yat-sen University, Guangzhou 510080, China. ${ }^{4}$ Department of Spine Surgery, Sun Yat-sen Memorial Hospital, Guangzhou 510120, China. ${ }^{5}$ Research Centre for Translational Medicine, First Affiliated Hospital of Sun Yat-sen University, No. 58 Zhongshan 2nd Road, Yuexiu District, Guangzhou 510080, China.

Received: 9 November 2017 Accepted: 26 April 2018

Published online: 03 May 2018

References

1. Kozlowski K, Lipska E. Hereditary dysplasia epiphysealis multiplex. Clin Radiol. 1967;18(3):330-6.

2. Silverman FN. C. John Hodson lecture. Reflections on epiphyseal dysplasias. AJR Am J Roentgenol. 1996;167(4):835-42.

3. Hecht JT, Nelson LD, Crowder E, Wang Y, Elder FFB, Harrison WR, Francomano CA, Prange CK, Lennon GG, Deere M, et al. Mutations in exon $17 \mathrm{~B}$ of cartilage oligomeric matrix protein (COMP) cause pseudoachondroplasia. Nat Genet. 1995;10(3):325-9.

4. Czarny-Ratajczak M, Lohiniva J, Rogala P, Kozlowski K, Perälä M, Carter L, Spector TD, Kolodziej L, Seppänen U, Glazar R, et al. A mutation in COL9A1 causes multiple epiphyseal dysplasia: further evidence for locus heterogeneity. Am J Hum Genet. 2001;69(5):969-80.

5. Muragaki Y, Mariman ECM, van Beersum SEC, Perala M, van Mourik JBA, Warman ML, Olsen BR, Hamel BCJ. A mutation in the gene encoding the [alpha]2 chain of the fibril-associated collagen IX, COL9A2, causes multiple epiphyseal dysplasia (EDM2). Nat Genet. 1996;12(1):103-5.

6. Bönnemann CG, Cox GF, Shapiro F, Wu J-J, Feener CA, Thompson TG, Anthony DC, Eyre DR, Darras BT, Kunkel LM. A mutation in the alpha 3 chain of type IX collagen causes autosomal dominant multiple epiphyseal dysplasia with mild myopathy. Proc Natl Acad Sci. 2000; 97(3):1212-7.

7. Chapman KL, Mortier GR, Chapman K, Loughlin J, Grant ME, Briggs MD. Mutations in the region encoding the von Willebrand factor a domain of matrilin-3 are associated with multiple epiphyseal dysplasia. Nat Genet. 2001;28(4):393-6.

8. Ballhausen D, Bonafé L, Terhal P, Unger SL, Bellus G, Classen M, Hamel BC Spranger J, Zabel B, Cohn DH, et al. Recessive multiple epiphyseal dysplasia (rMED): phenotype delineation in eighteen homozygotes for $<$ em $>$ DTDST $<1$ em> mutation R279W. J Med Genet. 2003;40(1):65-71.

9. Superti-Furga A, Hastbacka J, Wilcox WR, Cohn DH, van der Harten HJ, Rossi A, Blau N, Rimoin DL, Steinmann B, Lander ES, et al. Achondrogenesis type IB is caused by mutations in the diastrophic dysplasia sulphate transporter gene. Nat Genet. 1996;12(1):100-2.

10. Hastbacka J, Superti-Furga A, Wilcox WR, Rimoin DL, Cohn DH, Lander ES. Atelosteogenesis type $\|$ is caused by mutations in the diastrophic dysplasia sulfate-transporter gene (DTDST): evidence for a phenotypic series involving three chondrodysplasias. Am J Hum Genet. 1996;58(2): 255-62. 
11. Bonafé L, Hästbacka J, de la Chapelle A, Campos-Xavier AB, Chiesa C, Forlino A, Superti-Furga A, Rossi A. A novel mutation in the sulfate transporter gene $<$ em $>$ SLC26A2 </em> $(<e m>$ DTDST $</$ em $>)$ specific to the Finnish population causes de la Chapelle dysplasia. J Med Genet. 2008;45(12):827-31.

12. Superti-Furga A, Neumann L, Riebel T, Eich G, Steinmann B, Spranger J, Kunze J. Recessively inherited multiple epiphyseal dysplasia with normal stature, club foot, and double layered patella caused by a <em $>$ DTDST $</$ em $>$ mutation. J Med Genet. 1999;36(8):621-4.

13. Rossi A, Superti-Furga A. Mutations in the diastrophic dysplasia sulfate transporter (DTDST) gene (SLC26A2): 22 novel mutations, mutation review, associated skeletal phenotypes, and diagnostic relevance. Hum Mutat. 2001: 17(3):159-71.

14. Makitie O, Savarirayan R, Bonafe L, Robertson S, Susic M, Superti-Furga A Cole WG. Autosomal recessive multiple epiphyseal dysplasia with homozygosity for C653S in the DTDST gene: double-layer patella as a reliable sign. Am J Med Genet A. 2003;122a(3):187-92.

15. Barreda-Bonis AC, Barraza-García J, Parrón M, Pastor I, Heath KE, GonzálezCasado I. Multiple SLC26A2 mutations occurring in a three-generational family. Eur J Med Genet. 2017;

16. Karniski LP. Mutations in the diastrophic dysplasia sulfate transporter (DTDST) gene: correlation between sulfate transport activity and chondrodysplasia phenotype. Hum Mol Genet. 2001:10(14):1485-90.

Ready to submit your research? Choose BMC and benefit from:

- fast, convenient online submission

- thorough peer review by experienced researchers in your field

- rapid publication on acceptance

- support for research data, including large and complex data types

- gold Open Access which fosters wider collaboration and increased citations

- maximum visibility for your research: over $100 \mathrm{M}$ website views per year

At BMC, research is always in progress.

Learn more biomedcentral.com/submissions 